Howard, A. N., and Gresham, G. A. (1961). Lancet, 1, 397. Kannel, W. B., Dawber, T. R., Kagan, A., Revotski, N., and Stokes, J.,

Mason, J. K. (1963). Brit. med. f., 2, 1234

Morris, J. N. (1951). Lancet, 1, 69.

Peady, J. A., and Barley, R. G. (1957). Brit. Heart f., 19, 227.

Painter, R. C., Ralston, L. S., Fawcett, R. M., Zukel, W. J., and Lewis, R. H. (1960). f. Amer. med. Ass., 172, 1261.

Papp, C. (1952). Brit. Heart f., 14, 250.

Peel, A. A. F. (1955). Ibid., 17, 319.
Rodstein, M. (1956). Arch. intern. Med., 98, 84.

Russek, H. I., Zohman, B. L., Doerner, A. A., Russek, A. S., and White, L. G. (1951). ₹. Amer. med. Ass., 147, 1731.

Snow, P. J. D., Morgan Jones, A., and Daber, K. S. (1956). Brit. Hear f., 18, 435 .

Weitzman, D., and Smith, E. B. (1959). Brit. med. F., 2, 162.

Woods, J. D., Laurie, W., and Smith, W. G. (1963). Lancet, 2, 265.

Wright, H. B. (1960). Ibid., 2, 980.

Yater, W. M., Welsh, P. P., Stapleton, J. F., and Clark, M. L. (1951) Ann. intern. Med., 34, 352.

\title{
Five Weeks to Escape the Sleeping-pill Habit
}

\author{
IAN OSWALD,* M.A., M.D., D.SC., D.P.M. ; ROBERT G. PRIEST, $\dagger$ M.B., B.S., M.R.C.P.ED., D.P.M.
}

Brit. med. F., 1965, 2, 1093-1095

Ten per cent. of all National Health general practitioners' prescriptions are for hypnotic drugs (Ministry of Health, 1964). Large quantities of these drugs lie around in the average home. In Edinburgh hospital admissions for self-poisoning by barbiturates and non-barbiturate sedatives have increased fivefold in 10 years, though the death rate from suicide has fluctuated little (Kessel, 1965).

Belleville and Fraser (1957) reported that nurses' assessments of sleep revealed some tolerance to barbiturate hypnotics within the first 10 days, and tolerance apparently complete after three months. It is common for patients to describe taking sleepingpills for many years, of ten since an hospital admission for some minor procedure. Many will say they have tried to stop but found themselves unable to sleep "properly" without the accustomed hypnotic.

Persons taking very large amounts of barbiturates are liable to convulsions, delirium, insomnia, and other symptoms if their drugs are suddenly withdrawn. These features occur especially in the first week but can continue for two weeks (Fraser et al., 1964 ; Wulff, 1959).

In a previous investigation recent developments in knowledge of normal sleep were utilized to measure some neurophysiological functions after withdrawal of amphetamine from addicts. Return to normal took up to two months (Oswald and Thacore, 1963). Similar techniques have been used in the present study.

\section{Indices Measured}

It is now known that there are two kinds of sleep with sharply differing physiological characteristics (Jouvet, 1965). They alternate abruptly during the night. Initially humans always pass into the orthodox phase of sleep ("slow-wave" or "forebrain" phase) without rapid eye-movements but with electroencephalographic slow waves and "sleep spindles." After not less than 45 minutes (Oswald and Thacore, 1963; Rechtschaffen and Verdone, 1964), usually an hour or more, a sudden transition takes place to the paradoxical phase of sleep (" hind-brain," " rapid eye-movement," or "low voltage fast" sleep) when the E.E.G. is of low voltage and rapid jerky eyemovements occur. The paradoxical phase, with small but consistent individual variations, usually occupies just under $25 \%$ of the total night's sleep (Oswald et al., 1963; Rechtschaffen and Verdone, 1964 ; Williams, R. L., et al., 1964), but it occupies less than 35 minutes in the first two hours.

\footnotetext{
* Visiting Professor of Psychiatry, University of Western Australia,

Nedlands, Western Australia.
+ Lecturer in Psychiatry, University of Edinburgh.

Volunteers have been used as their own controls. All-night recordings of their E.E.G. and eye-movements have been made, though, as in the previous study (Oswald and Thacore, 1963), it is obvious in retrospect that recording of only the first two hours of sleep would have revealed the essential information. Recordings ran to some 35 miles $(56 \mathrm{~km}$.) of paper. Measurements made have again been of $(a)$ the delay between sleep onset (first E.E.G. "sleep spindles") and the first rapid eyemovements of the first paradoxical sleep of the night, $(b)$ the number of minutes of paradoxical sleep in the first two hours of sleep, and $(c)$ the total number of minutes of sleep and the total number of minutes of paradoxical sleep in the whole night. The last values have been combined for the pair of volunteers concerned to give the percentages of paradoxical sleep in the combined whole night shown in Figs. 1 and 2.

Volunteers were paid, and throughout the whole period of the experiments undertook to avoid late nights, alcohol, or other excesses. They were young adult normal males previously known to us and used in past studies.

\section{Experiment 1}

Two volunteers were used. After five baseline nights of sleep, for 14 consecutive nights they received $15 \mathrm{mg}$. of Mogadon

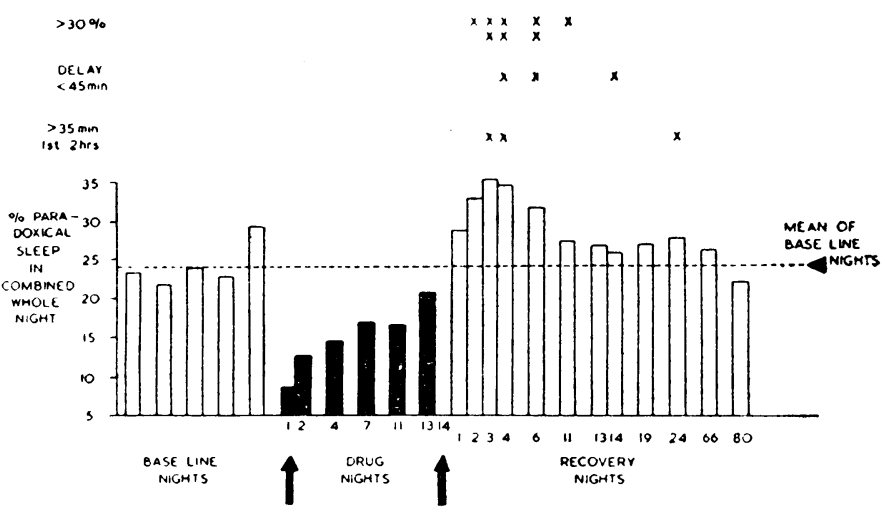

Fig. 1.-Effect of $15 \mathrm{mg}$. of Mogadon on the sleep of two men. When the drug is given each night the proportion of the night spent in paradoxical sleep (vertical columns) is decreased but then slowly rises. Withdrawal of drug causes a rise to ahnormal levels, maximal on the Withdrawal of drug causes a rise to ahnormal levels, maximal on the
third night. The time scale is not linear. Where either or both volunteers spent over $30 \%$ of the whole night in paradoxical sleep, had a delay period of less than 45 minutes between first falling asleep and first rapid eye-movements of paradoxical sleep, or spent more than 35 minutes of the first two hours of sleep in paradoxical sleep, a star has been placed over the night concerned. It will be seen that values beyond these criteria occurred only between the second and twenty-fourth recovery nights. 
(nitrazepam, an analogue of chlordiazepoxide), an effective new non-barbiturate hypnotic. Fig. 1 illustrates an initial effect of the drug on sleep (reduction of paradoxical sleep percentage), a diminution of that effect over the 14 nights, and a rebound after stopping the drug. On the second to sixth recovery nights the whole-night proportion of paradoxical sleep was abnormally high. As late as the twenty-fourth recovery night a clearly abnormal feature was still present, one man spending no less than 49 minutes of the first two hours of sleep in the paradoxical phase. A more intensive study of the recovery period was clearly indicated.

\section{Experiment 2}

Two volunteers (one of whom had been in Experiment A) took part, four months after the previous drug-taking. After five baseline nights they received $400 \mathrm{mg}$. (6 gr.) nightly of amylobarbitone sodium for nine nights (Fig. 2). The initial effect of the drug appeared to lessen ; therefore, mimicking what is sometimes done clinically, the dose was increased to $600 \mathrm{mg}$. for a further nine consecutive nights. Again after an initial effect the proportion of paradoxical sleep returned to normal.

Drug withdrawal once more caused a rebound. The proportion of paradoxical sleep rose to abnormally high values, and Fig. 2 seems to show, with some fluctuations, a slow return of this to normal over a period of weeks. The rebound was once more accompanied by abnormally short delays to first onset of paradoxical sleep and an increased amount of paradoxical sleep in the first two hours, persisting into the sixth week after withdrawal. On the 36th and 38th recovery nights one subject's delay period was 44 minutes and 45 minutes respectively, and on the 36th night the other volunteer spent 47 minutes of the first two hours in paradoxical sleep. In every case administration of the drug had earlier increased the delay to first onset of paradoxical sleep and diminished or abolished its presence in the first two hours.

Apart from the measurable changes illustrated in Figs. 1 and 2 other features of drug withdrawal were insomnia, nightmares, and a sense of having slept badly. Thus one volunteer in the second experiment averaged only three and a half hours' sleep on the first three recovery nights, thereafter quickly returning to his usual seven hours or so. The effect of short hours of sleep alone would actually be to decrease the percentage of paradoxical sleep on the nights concerned (the proportion always tends to rise slightly during the night). However, global sleep deprivation can eventually cause orthodox sleep to have priority (Berger and Oswald, 1962 ; Williams, H. L., et al., 1964), so the relatively low percentage value of the fourth recovery night may not have been merely a matter of chance. Nightmares were complained of by both volunteers during the first two recovery weeks.

\section{Discussion}

On the early drug nights the volunteers suffered a relative lack of paradoxical sleep. More extreme deprivation, effected by selective awakening, can cause a subsequent " compensatory" increase (Dement, 1960 ; Jouvet et al., 1964 ; Kales et al., 1964). This phenomenon cannot explain the present observations, there being no evidence that so small a degree of selective deprivation could cause such a large or prolonged rebound as that seen here.

Miller (1964) and Rushton and Steinberg (1964) gave rats amylobarbitone over a period to make them, as it were, less fearful. When the drug was stopped they became fearful again. Examination of the data of those authors reveals that the rats whose amylobarbitone was stopped were left consistently more fearful than others which had received saline throughout. The development of tolerance to drugs, followed by rebound and slow recovery after withdrawal, is not understood but may be along lines suggested by Collier (1965).

In our experiments drug-induced fast activity in the E.E.G. was discernible into the third withdrawal night after the nonbarbiturate, suggesting a slower elimination of that drug, which may explain why maximum abnormalities were delayed till the third recovery night. This should not be taken to mean that the non-barbiturate is more or less dangerous in clinical practice. The manufacturers advise us that as much as $300 \mathrm{mg}$. overdosage (60 tablets) has proved not serious.

Nightmares were complained of on nights when there was an elevated whole-night percentage of paradoxical sleep. The paradoxical phase of sleep is the kind of sleep in which dreaming is known to occur (Dement and Kleitman, 1957). Nightmares occurred when there was evidently an increased " pressure," as it were, towards that kind of sleep. Nightmares have similarly arisen in our laboratory at other times when this "pressure" was increased-namely, after withdrawal of tranylcypromine from an addict (Le Gassicke et al., 1965) and when oral L-tryptophan has been given to patients with idiopathic narcolepsy (Evans and Oswald, 1965).

We do not know why we sleep; we can only say that the brain processes underlying normal sleep, reflected in the functions we have been able to measure, were disturbed by hypnotic drugs and that return to normal took a matter of weeks, whatever the reason for so slow a return may have been.

\section{Summary}

In two experiments volunteers received either a nonbarbiturate hypnotic or sodium amylobarbitone nightly for up to 18 nights. Their all-night sleep was studied. Nightmares occurred at first after stopping the drug, and a number of measurable neurophysiological functions took over five weeks to return to normal. Attention is drawn to the difficulty experienced by some patients in renouncing the use of sleeping pills.

Note.-Since the preparation of this article for publication further experiments in this laboratory, conducted by J. I. Evans and others, have shown similar patterns after administration

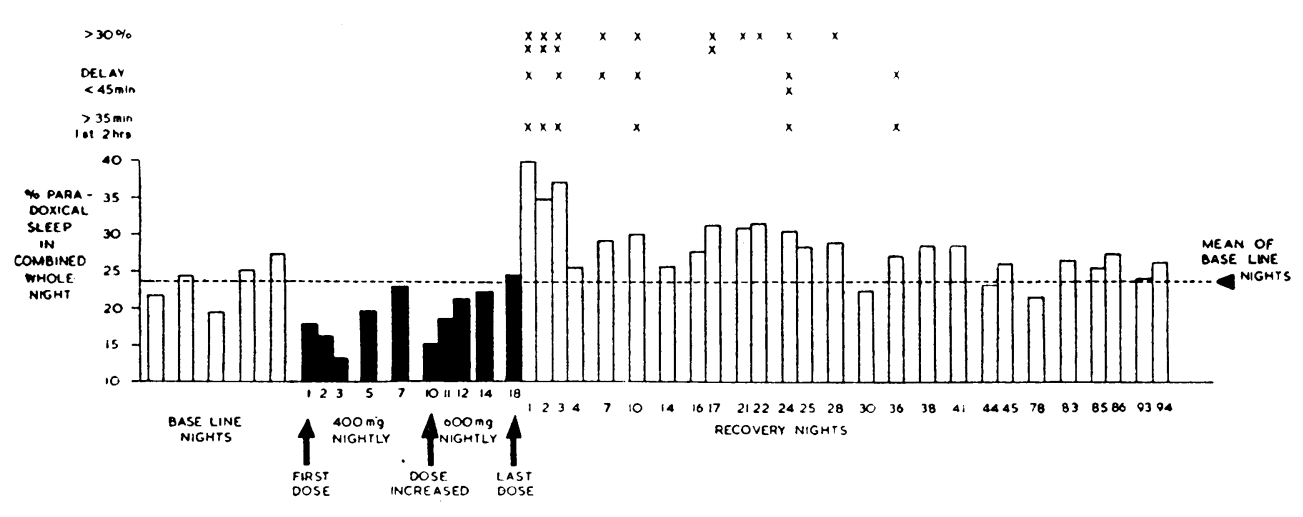

FIG. 2.-Effect of sodium amylobarbitone on the sleep of two men. Again the volunteers serve as their own controls. The hypnotic at first causes suppression of paradoxical sleep and withdrawal a rebound. The stars indicate where either or both volunteers on the night concerned gave values beyond the arbitrary limits indicated. The stars are seen only after drug withdrawal and peter out in the sixth recovery week. The time scale is not linear. 
and withdrawal of $200 \mathrm{mg}$. of sodium amylobarbitone nightly.

The investigation was possible only because of the objectivity and generosity of Roche Products Ltd. and of Dr. M. Duffus, of their Department of Clinical Research. Mr. A. Jamieson, Mr. S. Lewis, Mr. J. Noble, and Sister E. Falconer and her staff at the Royal Edinburgh Hospital collaborated.

\section{REFERENCBS}

Belleville, R. E., and Fraser, H. F. (1957). F. Pharmacol. exp. Ther., $120,469$.

Berger, R. J., and Oswald, I. (1962). 7. ment. Sci., 108, 457.

Collier, H. O. J. (1965). Nature (Lond.), 205, 181.

Dement, W. (1960). Science, 131, 1705.

- and Kleitman, N. (1957). \%, exp. Psychol., 53, 339.

Bvans, J. I., and Oswald, I. (1965). Electroenceph. clin. Neurophysiol., In press.

Fraser, H. F., Isbell, H., Eisenman, A. J., Wikler, A., and Pescor, F. T. (1954). Arch. intern. Med., 94, 34
Jouvet, D., Vimont, P., Delorme, F., and Jouvet, M. (1964). C. R. Soc. Biol. (Paris), 158, 756.

Jouvet, M. (1965). In Sleep Mechanisms, edited by K. Akert, G. Bally, and J. P. Schadé. Elsevier, Amsterdam.

Kales, A. Hoedemaker, F. S., Jacobson, A., and Lichtenstein, E. L. (1964). Nature (Lond.), 204, 1337.

Kessel, W. I. N. (1965). Brit. med. f. In press.

Le Gassicke, J., Ashcroft, G. W., Eccleston, D., Evans, J. I., Oswald, I., and Ritson, E. B. (1965). Brit. F. Psychiat., 111, 357.

Miller, N. E. (1964). In Animal Behaviour and Drug Action, Ciba Symposium, edited by $\mathrm{H}$. Steinberg. Churchill, London.

Ministry of Health (1964). Recent N.H.S. Prescribing Trends. H.M.S.O., London.

Oswald, I., Berger, R. J., Jaramillo, R. A., Keddie, K. M. G., Olley, P. C., and Plunkett, G. B. (1963). Brit. F. Psychiat., 109, 66.

and Thacore, V. R. (1963). Brit. med. F., 2, 427.

Rechtschaffen, A., and Verdone, P. (1964). Perceptual and Motor Skills, 19, 974.

Rushton, R., and Steinberg, H. (1964). In Animal Behaviour and Drug Action Ciba Symposium, edited by $\mathrm{H}$ Steinberg. Churchill, Londan

Williams, H. L. Hammack, J. T., Daly, R. L., Dement, W. C., and Lubin, A. (1964). Electroenceph. clin. Neurophysiol., 16, 269.

Williams, R. L. Agnew, H. W., and Webb, W. B. (1964). Ibid., 17, 376.

Wulff, M. H. (1959). The Barbiturate Withdrawal Syndrome., Munksgaard, Copenhagen.

\title{
Variation of Bowel Habit in Two Population Samples
}

\author{
A. M. CONNELL,* M.B., M.R.C.P.ED. ; CLARE HILTON, $\dagger$ M.B., B.S., D.oBST.R.C.o.g.; \\ G. IRVINE, $\ddagger$ L.R.C.P., L.R.C.S.ED. ; J. E. LENNARD-JONES,§ M.D., M.R.C.P. ; J. J. MISIEWICZ,§ M.B., B.S., B.SC.
}

Brit. med. F., 1965, 2, 1095-1099

It is often assumed that a healthy person has one bowel action each day, and there have been suggestions that a daily habit is not only natural but necessary. Few definitive studies of bowel habit exist, and the limits of normality are undefined. It has been suggested that normal limits cannot be set (Parks, 1943), and one standard text appears to imply that anything from one bowel action every few weeks or months to 24 bowel actions a day can be regarded as normal (Keele and Neil, 1961). Some definition of normal bowel habit is important in studies of persons complaining of " diarrhoea" or " constipation" where it is necessary to distinguish clearly between normal and abnormal. The studies now reported were undertaken to define the range of bowel habit in normal persons seen at health inspections in a factory and in patients seen at a general medical practitioner's surgery. Our interest in this study lay not so much in minor variations within the normal range, say between seven and ten bowel actions a week, but in defining the outside limits of normality. The opportunity has also been taken to determine the subjects' opinions about their bowel habit and the extent of the laxative habit in these populations.

\section{Method of Inquiry and Definitions}

The interviews were conducted by doctors or by nursing sisters specially trained for this work. All the interviewers used' the following form:

\begin{tabular}{|c|c|c|}
\hline Country of origin & & Date \\
\hline $\begin{aligned} & \text { Have you had }- \text { Typhoid } \\
& \text { Dysentery } \\
& \text { Food-poisoning }\end{aligned}$ & $\begin{array}{l}\text { yes/no } \\
\text { yes/no } \\
\text { yes/no }\end{array}$ & \\
\hline How many bowel actions do you have? & /day & $\begin{array}{l}\text { loose } \\
\text { formed } \\
\text { hard }\end{array}$ \\
\hline \multicolumn{2}{|c|}{ Have you had any change in bowel habit in past year? } & yes/no \\
\hline Do you take salts or laxatives & yes/no & $\begin{array}{l}\text { lweek } \\
\text { /month }\end{array}$ \\
\hline $\begin{aligned} & \text { Do you regard yourself as - normal ? } \text { loose? } \\
& \text { constipated ? }\end{aligned}$ & & \\
\hline
\end{tabular}

It will be seen that, in addition to details of the number of bowel actions a day, the subjects were asked to state the consistency of the stool, the occurrence of any change in bowel habit in the previous year, any history of dysentery, and whether they considered themselves normal or not. Inquiries were also made into laxative habits.

The subjects were placed into six groups with respect to bowel habit: (1) those who had an action twice a week or less frequently ; (2) those who had an action three or four times a week ; (3) those who had an action five to seven times a week; (4) those who had an action more often than once a day but fewer than three times a day; (5) those who had an action three times a day ; (6) those who had more than three bowel actions daily.

Those who took laxatives were divided arbitrarily into those who took them more often than once a week and those who took them less frequently.

\section{Part I. Results in an Industrial Community}

\section{G. IRVINE, A. M. CONNELL, J. E. LENNARD-JONES, J. J. MISIEWICZ}

The subjects studied were drawn from all sections of the population of three factories typical of many in the greater London area. In all, 1,055 persons were interviewed, comprising 655 women and 400 men. The age and sex distribution is shown in Table I. As is inevitable from a study of an

* Lecturer in Clinical Science, Royal Victoria Hospital, Belfast ; late Member of Scientific Staff'Medical Research Council, Gastroenterology Research Unit, Central Middlesex Hospital, London.

t Late Assistant in General Practice.

¥ Company Medical Adviser, T. Wall and Sons (Meat and Handy Foods) Ltd., London.

$\$$ Member of Scientific Staff Medical Research Council, Gastroenterology Research Unit, Central Middlesex Hospital, London. 